\title{
The Application Comparison of Z-score Forewarning Model for Chinese Listed Real Estate Industry Company
}

\author{
Yun SUN \\ International Business Faculty \\ Beijing Normal University, Zhuhai \\ Zhuhai, China \\ Samsunyun@163.com \\ Xun ZHAO \\ Faculty of Social Science \\ University of Macau \\ Macau, China \\ 58107709@qq.com
}

\author{
Lihong CHEN \\ Guangzhou GET Finance Holdings Co., Ltd \\ Guangzhou, China \\ 1528864058@qq.com
}

\author{
Shaosong WANG* \\ School of Business \\ Macau University of Science and Technology \\ Macau SAR, China \\ *Corresponding Author: sswang@must.edu.mo
}

\begin{abstract}
When the risk of the enterprises accumulates to a certain level, it would worsen into crisis. Therefore, how to combine the financial early warning means with the crisis prediction and risk prevention still need to research in greater depth. Real estate industry can affect its upstream and downstream firms, such as financial institutions, developers, building materials industry and etc. As a result, after compared and reviewed the domestic and foreign study of financial early warning theory, this paper chose $\mathrm{Z}$-score model and real estate industry as the subject from 2008 to 2012 . We focus on the reason why Z-score model cannot apply well in Chinese real estate industry and put forward some suggestions about how to modify the model and clarified the orientation of further study.
\end{abstract}

Keywords-financial forewarning; Z-score model; application comparison

\section{INTRODUCTION}

As the leader of the national economy, Chinese real estate industry is having obvious bubble and the real estate enterprise's survival environment is worsening since 2008. And thus, the possibility of financial crisis is increasing. The relationship between real estate enterprises and other ranges of industries is significantly related, such as the downstream building materials, decoration, housing marketing, and the upstream such as banking, engineering etc. Therefore, if a crisis in the real estate industry exists, lots of related industries will be implicated, even the healthy and stable development of the entire national economy will be affected. Consequently, it is important to construct a reasonable financial early-warning model, in order to detect the crisis of real estate enterprises and take effective measures as soon as possible.

Foreign studies began to explore the financial earlywarning model from about 1930, and the domestic financial crisis warning research has only been developed for more than ten years. In summary, these models can be divided into three generations [1], as shown in table 1.

TABLE I. FOREWARNING MODEL GENERATIONS

\begin{tabular}{|c|l|l|}
\hline Generations & \multicolumn{1}{|c|}{ Models } \\
\hline 1st & Single variable forecast model \\
\hline \multirow{3}{*}{2 nd } & Multiple linear discriminant analysis \\
\cline { 2 - 3 } & EOF model \\
\cline { 2 - 3 } & $\begin{array}{l}\text { Conditioning } \\
\text { probability mode }\end{array}$ & Logistic regression mode \\
\cline { 2 - 2 } & Artificial Neural Network Model regression mode \\
\hline
\end{tabular}

The first generation of single variable model cannot reflect the financial status of enterprises comprehensively; as a result, the model is not widely used.

The second generation model is more representative named multiple linear discriminant model. Among them, the $\mathrm{Z}$ model is the most typical multivariate linear model. Edward I. Altman first proposed the Z-score model in 1968 [2]. In that study, Altman used multiple discriminant analysis (MDA) to carry on the early warning of the financial crisis. More specifically, he selected 33 financial crisis enterprises bankruptcy from 1946 to 1965 and 33 another companies without the occurrence of financial crisis of enterprises as the sample to establish a model of Z-score.

The third generation model is artificial neural network (ANN) which is found at the end of twentieth Century. Since the model is nonlinear and contains qualitative characteristics and is conducive to the study to be the most changeful financial environment, it is gradually used in the financial crisis warning research area. Sharda and Odom [3] combined the neural network model with the financial crisis early-warning research for the first time and apply the artificial neural network to the financial crisis warning system in 1990. However, because the theoretical basis of ANN model is relatively weak, scientific 
and correctness need further research and verification, therefore the frequency of using the model in financial early warning system has been decreased.

\section{DATA AND METHODOLOGY}

\section{A. Data Selection}

We select the real estate companies listed on the Shanghai and Shenzhen stock markets as our samples, and the data comes from the financial reports of listed companies for the past 5 years. The samples were divided into ST and non ST groups. In the non ST group, we use 30 real estate listed companies as the research object. Considering some real estate listed companies have not yet disclosed after the 2016 financial report and the possibility of Restatement (dating back 3 years), we finally record 30 non ST companies from 2008 to 2012 with total 150 sets of financial data points. For the ST group, we select 10 real estate listed companies as a sample, defined by the special treatment of the previous year as the base year (zeroth years), two years ago for the "first years", and so on, with the financial data record 5 years a total of 50 data points. In addition, the data processing tools in this paper are used average Z-value contrast and model critical point contrast methods. Furthermore, we use the balance of the financial expense account instead of interest expense.

\section{B. Methodology}

We use Z-score model to explore the empirical analysis, since the Z-score model is more appropriated for our study than other models, such as in sample size, recognition and operability. The Z-score model in this study is as follows:

$$
Z=1.2 X_{1}+1.4 X_{2}+3.3 X_{3}+0.6 X_{4}+0.99 X_{5}
$$

The detailed definition of variables and Z-score explanations are shown in Table II and III.

\section{TABLE II. MODEL PROXIES}

\begin{tabular}{|c|c|c|}
\hline Variables & Representative value & Calculation \\
\hline X1 & $\begin{array}{l}\text { Current Capital/Total } \\
\text { Asset }\end{array}$ & $\begin{array}{lr}\text { (Current } & \text { Asset } \\
\text { Liability)/Total Asset }\end{array}$ \\
\hline $\mathrm{X} 2$ & $\begin{array}{l}\text { Retained capital/Total } \\
\text { Asset }\end{array}$ & $\begin{array}{l}\text { (Surplus reserves+Retained } \\
\text { Earningd)/Total Asset }\end{array}$ \\
\hline X3 & EBIT/Total Asset & $\begin{array}{lcc}\text { (Tot ju } \quad \text { al } & \text { NI+Interest } \\
\text { Expences)/Total Asset } & \\
\end{array}$ \\
\hline \multirow{2}{*}{ X4 } & \multirow[t]{2}{*}{$\begin{array}{l}\text { Equity market } \\
\text { value/Total liabilities } \\
\text { book value }\end{array}$} & $\begin{array}{l}\text { Tradable: Stock price } \times \text { Total } \\
\text { outstanding/Total liabilities book } \\
\text { value }\end{array}$ \\
\hline & & $\begin{array}{l}\text { Non-tradable: net asset value per } \\
\text { share } \times \text { Total non-tradable shares/ } \\
\text { Total liabilities book value }\end{array}$ \\
\hline X5 & $\begin{array}{l}\text { Total Asset Turnover } \\
\text { Ratio }\end{array}$ & Sales revenue/Total Asset \\
\hline
\end{tabular}

TABLE III. MODEL JUDGEMENT STANDARD

\begin{tabular}{|c|l|l|}
\hline $\mathbf{Z}$ value & \multicolumn{1}{|c|}{ Descriptions } & \multicolumn{1}{c|}{ Conclusions } \\
\hline $\mathbf{Z}>\mathbf{2 . 6 7 5}$ & $\begin{array}{l}\text { In good financial } \\
\text { condition }\end{array}$ & Unlikely to go bankcrupt \\
\hline $\mathbf{2 . 6 7 5}>\mathbf{Z}>\mathbf{1 . 8 1}$ & $\begin{array}{l}\text { The financial situation } \\
\text { is very unstable }\end{array}$ & $\begin{array}{l}\text { Gray area, cannot determine the } \\
\text { possibility of bankcrupcy }\end{array}$ \\
\hline $\mathbf{Z}<\mathbf{1 . 8 1}$ & Under financial crises & Likely to go bankcrupt \\
\hline
\end{tabular}

\section{RESULTS}

\section{A. Critical Value Contrast}

The distribution of $\mathrm{Z}$ values in the non ST group and the ST group are shown in Table IV and Table V, respectively. In the non ST group, according to the setting of the critical point by Altman, the theoretical $\mathrm{Z}$ value of the enterprise should be more than 2.675; otherwise it is regarded as a miscarriage of justice. Similarly, in the ST group, the $\mathrm{Z}$ value should fall within the range of no more than 1.81. The misclassification rate is equal to the number of one-sided values not set at the fixed $\mathrm{Z}$ value, except for the total number of samples in the group.

As can be seen from table IV, the average false rate of the Z-score model in non ST group is as high as $82.67 \%$. Most of the companies in the non ST group should have been healthy, good financial situation. However, their $\mathrm{Z}$ values are mostly distributed in the "2.675 > Z > 1.81" (financial status unknown) and "Z" 1.81 "(the possibility of bankruptcy large) the two intervals. The number of total samples were $40.67 \%$, 42\%, respectively, and the $\mathrm{Z}$ value falls in 2012 accounted for $56.67 \%$ of the total number of samples in the proportion of " $\mathrm{Z}<1.81 "$ companies, which is far higher than other years.

In contrast, the applicability of the Z-score early warning model in the ST group is higher than the non ST group. As shown in Table $\mathrm{V}$, the average false positive rate of the $\mathrm{Z}$ value in the ST group is $20 \%$. Zeroth years is a year ago by special treatment, in which $\mathrm{Z}>1.81$ companies accounted for $90 \%$. The company in the next year will be special treatment, indicated that the early warning effect. Similarly, in the 1 4 years, that is, before the special treatment $2 \sim 5$ years, most of the company's $\mathrm{Z}$ value is less than 1.81, indicating that the Zscore model of the financial crisis warning function is still better.

In combination of the two groups, the critical point of Altman is used to judge the financial situation of Listed Companies in China's real estate industry, and the prediction accuracy is less than $50 \%$.

TABLE IV. NON-ST GROUP Z-VALUE DISTRIBUTION

\begin{tabular}{|c|c|l|c|l|c|l|c|}
\multirow{2}{*}{ Year } & \multicolumn{2}{|c|}{ Z>2.675 } & \multicolumn{2}{|c|}{$\mathbf{2 . 6 7 5} \geq \mathbf{Z}>\mathbf{1 . 8 1}$} & \multicolumn{2}{|c|}{$\mathbf{Z} \leq \mathbf{1 . 8 1}$} & \multirow{2}{*}{$\begin{array}{c}\text { Misjudge } \\
\text { rate }\end{array}$} \\
\cline { 2 - 7 } & $\#$ & proportion & $\#$ & proportion & $\#$ & proportion & \\
\hline $\mathbf{2 0 1 2}$ & 5 & $16.67 \%$ & 8 & $26.67 \%$ & 17 & $56.67 \%$ & $83.33 \%$ \\
\hline $\mathbf{2 0 1 1}$ & 7 & $23.33 \%$ & 11 & $36.67 \%$ & 12 & $40.00 \%$ & $76.67 \%$ \\
\hline $\mathbf{2 0 1 0}$ & 5 & $16.67 \%$ & 14 & $46.67 \%$ & 11 & $36.67 \%$ & $83.33 \%$ \\
\hline $\mathbf{2 0 0 9}$ & 4 & $13.33 \%$ & 14 & $46.67 \%$ & 12 & $40.00 \%$ & $86.67 \%$ \\
\hline $\mathbf{2 0 0 8}$ & 5 & $16.67 \%$ & 14 & $46.67 \%$ & 11 & $36.67 \%$ & $83.33 \%$ \\
\hline Avg. & & $17.33 \%$ & & $40.67 \%$ & & $42.00 \%$ & $82.67 \%$ \\
\hline
\end{tabular}

TABLE V. ST GROUP Z-VALUE DISTRIBUTION

\begin{tabular}{|l|c|l|l|l|l|l|l|}
\hline Year & \multicolumn{2}{|c|}{ Z>2.675 } & \multicolumn{2}{|c|}{$\mathbf{2 . 6 7 5} \mathbf{Z} \mathbf{>} \mathbf{1 . 8 1}$} & \multicolumn{2}{|c|}{$\mathbf{Z \leq 1 . 8 1}$} & $\begin{array}{c}\text { Misjudge } \\
\text { rate }\end{array}$ \\
\cline { 2 - 7 } & $\#$ & proportion & $\#$ & proportion & $\#$ & proportion & \\
\hline $\mathbf{2 0 1 2}$ & 1 & $10.00 \%$ & 0 & $0.00 \%$ & 9 & $90.00 \%$ & $10.00 \%$ \\
\hline $\mathbf{2 0 1 1}$ & 2 & $20.00 \%$ & 1 & $10.00 \%$ & 7 & $70.00 \%$ & $30.00 \%$ \\
\hline $\mathbf{2 0 1 0}$ & 1 & $10.00 \%$ & 0 & $0.00 \%$ & 9 & $90.00 \%$ & $10.00 \%$ \\
\hline $\mathbf{2 0 0 9}$ & 1 & $10.00 \%$ & 1 & $10.00 \%$ & 8 & $80.00 \%$ & $20.00 \%$ \\
\hline $\mathbf{2 0 0 8}$ & 1 & $10.00 \%$ & 2 & $20.00 \%$ & 7 & $70.00 \%$ & $30.00 \%$ \\
\hline Avg. & & $12.00 \%$ & & $8.00 \%$ & & $80.00 \%$ & $20.00 \%$ \\
\hline
\end{tabular}




\section{B. Z Value Mean Contrast}

In the non ST group, all the $\mathrm{Z}$ values averaged greater than 2.675, the enterprise was judged to be in good financial condition, in line with the actual situation. In the ST group, the average value of all $\mathrm{Z}$ values is less than 1.81, and the enterprises are judged to have serious financial crisis, which is also in line with the actual situation.

The above two methods can reach the critical point, the definition of Z-score model is effective in the overall judgment, but in individual judgment but there is greater error, it also shows that the real estate listed companies $\mathrm{Z}$ value of the standard deviation is greater, the difference of the $\mathrm{Z}$ values significantly.

TABLE VI. BETWEEN GROUP AVERAGE Z-VALUE

\begin{tabular}{|c|c|c|c|c|c|c|}
\hline Group & $\mathbf{2 0 1 2}$ & $\mathbf{2 0 1 1}$ & $\mathbf{2 0 1 0}$ & $\mathbf{2 0 0 9}$ & $\mathbf{2 0 0 8}$ & 5 year average \\
\hline Non ST & 4.738 & 4.746 & 4.762 & 4.769 & 4.848 & 4.781 \\
\hline ST & 0.924 & 0.899 & 0.919 & 0.916 & 0.913 & 0.912 \\
\hline
\end{tabular}

\section{Index Mean Comparison}

According to the above analysis can draw the average $\mathrm{Z}$ number in the non ST group and ST group were significantly different, but there are still some errors in the individual samples, so the average value of each index in the model through the comparative analysis to determine whether the variables significantly. Table VI lists the average values and their differences between the non ST group and the ST group. Among them, $\mathrm{K}=$ (non ST enterprise, -ST enterprise) /ST enterprise

It can be seen from Table VII, X1, X2, X3, X4 in the difference between the two groups is very large, which $\mathrm{X} 1$ the most obvious difference, and the difference in X5 between the two groups is relatively small, preliminary judgment can be made of X1, X2, X3, X4 of the 4 indicators in judging whether the listed companies appear the financial crisis is effective.

TABLE VII. MEAN VALUE COMPARISON TABLE

\begin{tabular}{|c|c|c|c|c|c|c|}
\hline Year & Group & X1 & $\mathrm{X} 2$ & X3 & $\mathrm{X} 4$ & X5 \\
\hline \multirow{3}{*}{2012} & Non ST & 0.5536 & 0.0419 & 0.0437 & 6.0687 & 0.2315 \\
\hline & ST & 0.0442 & -0.1700 & -0.0297 & 1.5383 & 0.2869 \\
\hline & K\% & 1151.65 & -124.63 & -247.31 & 294.50 & -19.30 \\
\hline \multirow{3}{*}{2011} & Non ST & 0.5557 & 0.0428 & 0.0436 & 6.0788 & 0.2310 \\
\hline & ST & 0.0309 & -0.1661 & -0.0341 & 1.5171 & 0.2995 \\
\hline & K\% & 1697.45 & -125.74 & -227.65 & 300.68 & -22.86 \\
\hline \multirow{3}{*}{2010} & Non ST & 0.5580 & 0.0438 & 0.0437 & 6.0974 & 0.2308 \\
\hline & ST & 0.0365 & -0.1605 & -0.0312 & 1.4944 & 0.3093 \\
\hline & K\% & 1969.36 & -46.74 & 4648.78 & 387.33 & 74.61 \\
\hline \multirow{3}{*}{2009} & Non ST & 0.5595 & 0.0445 & 0.0437 & 6.1073 & 0.2294 \\
\hline & ST & 0.0347 & -0.1572 & -0.0308 & 1.4691 & 0.3179 \\
\hline & K\% & 1510.94 & -128.31 & -242.14 & 315.71 & -27.84 \\
\hline \multirow{3}{*}{2008} & Non ST & 0.5598 & 0.0447 & 0.0438 & 6.1115 & 0.2271 \\
\hline & ST & 0.0296 & -0.1539 & -0.0290 & 1.4419 & 0.3271 \\
\hline & K\% & 1794.00 & -129.03 & -251.37 & 323.86 & -30.56 \\
\hline
\end{tabular}

\section{Confirmatory Analysis: Pearson Correlation Analysis}

Pearson correlation analysis was performed for 5 variables in the ST group and the non ST group, and the output results were shown in Table VII and Table VIII. The "X1ST" in the table represents the value of the ST group enterprise variable $\mathrm{X} 1$. Variables such as X2, X3, X4, X5, and Z are the same.

As can be seen in Table VIII in the ST group, variables X1, $\mathrm{X} 2, \mathrm{X} 3, \mathrm{X} 4$ are significantly related to $\mathrm{Z}$ values, that is, to use these 4 variables to interpret the $Z$ values of the ST group is reasonable and valid. In contrast, in the non ST group, at a significant level of 0.01 , the significant difference was only X4, and the effects of other variables were not ideal.

TABLE VIII. CORRELATION ANALYSIS

\begin{tabular}{|c|c|c|c|c|c|c|}
\hline \multicolumn{2}{|c|}{} & X1 & X2 & X3 & X4 & X5 \\
\hline \multirow{2}{*}{\begin{tabular}{c} 
ST \\
\cline { 2 - 7 }
\end{tabular}} & Pearson & $0.673^{* *}$ & $0.555^{* *}$ & $0.649^{* *}$ & $0.710^{* *}$ & 0.201 \\
\cline { 2 - 7 } & Sig & 0.000 & 0.000 & 0.000 & 0.000 & 0.163 \\
\cline { 2 - 7 } & $\mathrm{N}$ & 50 & 50 & 50 & 50 & 50 \\
\hline \multirow{2}{*}{$\begin{array}{c}\mathbf{Z} \\
\text { nonST }\end{array}$} & Pearson & -0.025 & 0.011 & -0.058 & 00.012 & -0.156 \\
\cline { 2 - 7 } & Sig & 0.760 & 0.895 & 0.484 & 0.000 & 0.057 \\
\cline { 2 - 7 } & $\mathrm{N}$ & 150 & 150 & 150 & 150 & 150 \\
\hline
\end{tabular}

\section{DISCUSSION}

From the individual misclassification rate, the applicability of the Z-score model in the ST group is higher than that of the non ST group. In the non ST group, the average false positive rate was as high as $82.67 \%$, while in the ST group the false positive rate was only $20 \%$, much lower than that in the non ST group. Combining the empirical research of the two groups, the applicability of the Z-score model in the real estate listed companies is relatively low.

From the validity of the variable, the 5 variables in the Zscore model are not applicable to all. In the ST group, there are 4 variables, $\mathrm{X} 1, \mathrm{X} 2, \mathrm{X} 3, \mathrm{X} 4$, which are significant, whereas in the non ST group, only $\mathrm{X} 4$ is significant. According to the index average, the difference between the 4 variables of $\mathrm{X} 1$, $\mathrm{X} 2, \mathrm{X} 3, \mathrm{X} 4$ in the ST group and the non ST group is obvious, that is, the financial crisis can be predicted from the change of these variables. Similar results were also obtained by Pearson correlation analysis. On the whole, X5 this variable is less significant, may be related to China's real estate policy, curb part of the sales revenue.

From the coefficient of the model, in the ST group, the positive and negative coefficients of each variable are consistent with the model, while in the non ST group, the gap is very large.

From the mean value of $\mathrm{Z}$, the $\mathrm{Z}$ value is reliable for predicting financial distress. In the non ST group, the $\mathrm{Z}$ mean is greater than 2.675, and the enterprise is judged to be in good financial condition and is in line with the actual situation. In the ST group, the average $\mathrm{Z}$ is less than 1.81, the enterprises are judged to be more serious financial crisis, but also in line with the actual situation. The critical point of the definition of the Z-score model is effective in the overall judgment, but there are large errors in the individual judgment. It also shows that the standard deviation of $\mathrm{Z}$ value of real estate listed companies is greater. 
The overall effect of the $\mathrm{Z}$ value is not very ideal, and the reality at the year is 2011, two years before that period. While in group ST the most effective time is 1 years ago by the special treatment, then is 3 4 years ago. In the first 2 years and the first 5 years, the effect was not significant.

Based on the above analysis, when the Z-score model is applied to Chinese real estate listed companies, the average prediction accuracy of financial early warning is only about $50 \%$, and the results are not satisfactory. Some possible reasons are as follows:

Firstly, there is a big difference between the macro environment in China and the United States at that time. As China is now in a period of rapid development, many enterprises are in the growth period, and the debt ratio of these enterprises is generally higher. This will lead to the low X4. In addition, with the national macro-control of the real estate industry, the real estate sales revenue was artificially suppressed, resulting in inaccurate variable X5, which led to the calculation of $\mathrm{Z}$ value is low.

Secondly, the United States in the securities market and other aspects of the system are very different from China, for example, the United States does not limit the circulation of shares. For security reasons, some enterprises will limit the stock circulation in China, leading to the variable X4 in the calculation of the $\mathrm{Z}$ value and the original model has a certain difference.

\section{CONClusion}

The application of Z-score can be seen all over the world, as in Pan (2009)[4], Mare et al. (2017)[5], Strobel (2011)[6], to list just a few for example. However, it does not mean people can just take and use the formula of Z-score as it originally put out. As the current paper finds out, the index and weight of Zscore model are closely related to the selected sample industry. The real estate industry needs large upfront investment, which affects the magnitude of $\mathrm{Z}$. Therefore, it is necessary to adjust the model of industry. According to the empirical results, we can see that the application of the model in the real estate industry is not satisfactory, and the $\mathrm{Z}$ value is generally low.
The enterprise financial crisis is the potential danger in the development of the enterprise. If it happens, it may cause Domino effect, leading to the enterprise profit lose, the share price drops, even withdraw from the market and go bankrupt. China's real estate enterprises, as the lifeblood of the national economy, play an important role in the development of the country. Meanwhile, facing the increasingly fierce competition in the industry, as well as the continuous suppression of the real estate industry by foreign countries, the real estate financial crisis is becoming increasingly serious.

Based on this, the applicability of this Z-score model of financial early-warning model is used most of the listed companies in the Chinese real estate; we discuss this model in the paper and analyze the effect and the reason. In the critical point of the model, the critical point of the Z-score model is estimated with the statistical method of parameter estimation, and a new critical point is set up for the listed companies in the real estate of our country. Therefore, in order to make the Zscore model more effective, we should make a concrete analysis of the specific problems and establish a more accurate model with the listed companies and specific industry data.

\section{REFERENCES}

[1] WANG, Xiaoyan and LEI, Zhenhua, A comparative analysis of multivariable financial early warning model, China Township Enterprises Accounting, 2011,(09):18-20.

[2] Altman E.I., Financial Ratio, Discriminant Analysis and the Prediction of Corporate Bankruptcy Journal of Finance, 1968, (9): 589-609.

[3] M. D. Odom and R. Sharda, A Neural Network Model for Bankruptcy Prediction, Neural Networks, 1990 IJCNN International Joint Conference on, Vol. 2, 1990, pp. 163- 168.

[4] Pan, Wen-Tsao, Forecasting classification of operating performance of enterprises by ZSCORE combining ANFIS and genetic algorithm, Neural Computing and Applications,2009,18(8):1005 -1011.

[5] Mare, D. S., Moreira, F., and Rossi, R., Nonstationary Z-Score measures, European Journal of Operational Research, 1 July 2017, Vol.260(1), pp.348-358.

[6] Strobel, F., Bank insolvency risk and Z -score measures with unimodal returns, Applied Economics Letters, 01 November 2011, Vol.18(17), p.1683-1685. 